\title{
The endocannabinoid system as a possible target to treat both the cognitive and emotional features of post-traumatic stress disorder (PTSD)
}

\author{
Viviana Trezza ${ }^{1 *}$ and Patrizia Campolongo ${ }^{2 *}$ \\ 'Department of Sciences, Section of Biomedical Sciences and Technologies, University "Roma Tre," Rome, Italy \\ ${ }^{2}$ Department of Physiology and Pharmacology, Sapienza University of Rome, Rome, Italy
}

\author{
Edited by: \\ Jozsef Haller, Institute of \\ Experimental Medicine, Hungary

\section{Reviewed by:} \\ Irit Akirav, University of Haifa, Israel \\ Reinaldo N. Takahashi, Universidade \\ Federal de Santa Catarina, Brazil \\ István Gyertyán, Gedeon Richter \\ Plc., Hungary \\ *Correspondence: \\ Viviana Trezza, Department of \\ Sciences, Section of Biomedical \\ Sciences and Technologies, \\ University "Roma Tre," Viale G. \\ Marconi 446, 00146 Rome, Italy \\ e-mail:viviana.trezza@uniroma3.it; \\ Patrizia Campolongo, Department of \\ Physiology and Pharmacology, \\ Sapienza, University of Rome, \\ Piazzale A. Moro 5, \\ 00185 Rome, Italy \\ e-mail: patrizia.campolongo@ \\ uniroma1.it
}

\begin{abstract}
Post-traumatic stress disorder (PTSD) is a psychiatric disorder of significant prevalence and morbidity, whose pathogenesis relies on paradoxical changes of emotional memory processing. An ideal treatment would be a drug able to block the pathological over-consolidation and continuous retrieval of the traumatic event, while enhancing its extinction and reducing the anxiety symptoms. While the latter benefit from antidepressant medications, no drug is available to control the cognitive symptomatology. Endocannabinoids regulate affective states and participate in memory consolidation, retrieval, and extinction. Clinical findings showing a relationship between Cannabis use and PTSD, as well as changes in endocannabinoid activity in PTSD patients, further suggest the existence of a link between endocannabinoids and maladaptive brain changes after trauma exposure. Along these lines, we suggest that endocannabinoid degradation inhibitors may be an ideal therapeutic approach to simultaneously treat the emotional and cognitive features of PTSD, avoiding the unwanted psychotropic effects of compounds directly binding cannabinoid receptors.
\end{abstract}

Keywords: endocannabinoids, cannabis, memory, anxiety, trauma exposure
Post-traumatic stress disorder (PTSD) is a psychiatric disorder of significant prevalence and morbidity (Layton and Krikorian, 2002). In the overall population, more than two thirds of persons may experience a serious traumatic event at some point in lifetime (Javidi and Yadollahie, 2012). Although not everyone develops PTSD after experiencing a traumatic event, the lifetime prevalence of PTSD is high, being estimated as $8.2 \%$ in Europe and in the United States, up to $9.2 \%$ in Canada (Kessler et al., 1995; Darves-Bornoz et al., 2008; Van Ameringen et al., 2008). More than a third of PTSD patients fail to recover even after many years of treatment (Darves-Bornoz et al., 2008), showing a significant impairments in many aspects of health-related quality of life, including psychosocial functioning (Schelling et al., 1998).

Feeling afraid is a natural response to threats and triggers many physiological changes to prepare the body to defend against the danger or to avoid it. In PTSD, this reaction is changed or damaged. Even if anxiety is a common symptom of PTSD patients, the pathogenesis of the disorder relies on paradoxical changes of memory processing (Cohen et al., 2006; Parsons and Ressler, 2013). From a physiological point of view, memories characterized by a strong emotional salience tend to be well consolidated, they are often retrieved in our brain and therefore tend not to be extinct; from an evolutionary perspective, this is of crucial importance for survival. However, in PTSD patients, all or part of this processes may become maladaptive. Three symptom categories characterize the disorder: (1) persistent re-experience of the traumatic event; (2) persistent symptoms of increased arousal; and (3) persistent avoidance of stimuli associated with the trauma, which may include amnesia for important aspects of the traumatic event (Brewin, 2001). These symptoms reflect excessive retrieval of traumatic memories that are again consolidated, thus cementing the traumatic memory trace, and retaining its vividness and power to evoke distress for decades or even a lifetime (de Quervain et al., 2009). It appears from this symptomatology that three phases of memory processing may become maladaptive and of crucial importance in the development and maintenance of PTSD: consolidation, retrieval, and extinction.

PTSD is heterogeneous in its nature, and often associated with other psychiatric comorbidities; for these reasons, treating PTSD is rather difficult, and the disorder may persist over the patient's lifetime (Albucher and Liberzon, 2002). The therapeutic options to treat the anxiety symptoms of PTSD currently include serotonin reuptake inhibitors (SSRIs), serotonin-norepinephrine reuptake inhibitors (SNRIs), tricyclic antidepressants (TCAs), monoamine oxidase inhibitors (MAOi), anticonvulsants, atypical antipsychotics and benzodiazepines (Albucher and Liberzon, 2002). Although SSRIs emerge as the preferred first line treatment to treat the anxiety symptoms of PTSD (Dow and Kline, 1997; Ipser et al., 2006), a large proportion of patients fails to respond to these medications (Ipser et al., 2006). Furthermore, no suitable 
treatment is currently available to treat the maladaptive cognitive features of PTSD and/or to prevent its development. This limitation is due to the scarce knowledge of PTSD neurobiology that hampers the identification of new pharmacological targets to treat this disorder. As Albucher and Liberzon (2002) pointed out, the diversity of the symptoms such as flashbacks, nightmares, hyperarousal, avoidance, numbing, anxiety, anger, impulsivity, or aggression suggests the involvement of multiple neurotransmitter systems (Goodman et al., 2012; Packard and Goodman, 2012).

An ideal pharmacological treatment for PTSD would be a drug able to block the pathological over consolidation and continuous retrieval of the traumatic event, while enhancing its extinction and reducing the anxiety symptoms. Although no such drug is currently available, recent clinical (Fraser, 2009; Hauer et al., 2013; Neumeister et al., 2013) and preclinical (Lutz, 2007; Akirav, 2011; Berardi et al., 2012; Ganon-Elazar and Akirav, 2012) studies point to the endocannabinoid system as a possible ideal therapeutic target to treat both the emotional and cognitive dysfunctions characterizing PTSD (Neumeister, 2013).

The central endocannabinoid system is a neuroactive lipid signaling system in the brain which shows functional activity since early stages of brain development; by controlling neurotransmitter release, it plays a relevant role in brain function during both pre- and post-natal life (Fernandez-Ruiz et al., 2000; Harkany et al., 2007; Trezza et al., 2008; Campolongo et al., 2009b, 2011). The endocannabinoid system consists of cannabinoid receptors (CB1 and CB2), their endogenous lipid ligands (endocannabinoids) and the enzymatic machinery for endocannabinoid synthesis and degradation (Piomelli, 2003; Di Marzo et al., 2005). Due to the wide expression of cannabinoid receptors throughout limbic regions of the brain, endocannabinoids control both emotional behavior and cognitive processes (Riedel and Davies, 2005; Campolongo et al., 2007, 2009a; Hill and Gorzalka, 2009; Atsak et al., 2012; Campolongo et al., 2012). Thus, while preclinical studies assessing the consequences of cannabinoid receptor blockade or activation on emotional responses have yielded sometimes controversial results, consensus exists that endocannabinoids have an essential role in maintaining emotional homeostasis (Haller et al., 2002, 2004; Hill and Gorzalka, 2009; Moreira and Wotjak, 2010; Parolaro et al., 2010; Ruehle et al., 2012). Similarly, evidence exists that administration of cannabinoid drugs in animals influences memory consolidation, retrieval and extinction (Marsicano et al., 2002; Niyuhire et al., 2007; Marsicano and Lafenetre, 2009; Atsak et al., 2012; Campolongo et al., 2013). In particular, systemic administration of cannabinoid agonists impairs memory retrieval (Niyuhire et al., 2007) while facilitating memory extinction (Lutz, 2007). Direct evidence has been provided that endocannabinoids modulate emotional memory processing acting in the basolateral complex of the amygdala (BLA), in the hippocampus (de Oliveira Alvares et al., 2005, 2008; Campolongo et al., 2009a; Atsak et al., 2012) and in the prefrontal cortex (Egerton et al., 2006), key brain regions involved in memory consolidation, retrieval and extinction of emotionally arousing experiences (McGaugh, 2004; Quirk and Mueller, 2008; Roozendaal et al., 2008; Herry et al., 2010), and dysfunctional in PTSD patients (Bremner et al., 2008; Hughes and Shin, 2011). Interestingly, emerging empirical work has indicated a link between traumatic event exposure and cannabis use. Data from the National Comorbidity Study demonstrated that adults suffering from PTSD were three times more likely to have cannabis dependence as compared with those without PTSD (Kessler et al., 1995). Studies involving military veterans have demonstrated an even higher rate of cannabis abuse among military veterans with PTSD (Stewart et al., 1998; Bonn-Miller et al., 2011). A positive association between PTSD and cannabis use among teenagers has also been reported (Cornelius et al., 2010). These results could be partially explained by recent data demonstrating that PTSD patients present important changes of plasma endocannabinoid levels and elevation in amygdala-hippocampal-cortico-striatal CB1 receptor availability (Hauer et al., 2013; Neumeister, 2013; Neumeister et al., 2013). The comorbidity between cannabis abuse and PTSD is always described in literature as a negative aspect, with the increase in substance abuse after a disaster as a cause for public long-term health consequences. However, another side of the coin needs to be considered. It is possible that PTSD patients use cannabis as a self-medication. In support of this hypothesis, one study among Vietnam veterans indicated that cannabis use was helpful in managing PTSD symptoms, with particular respect to the hyperarousal state (Bremner et al., 1996). It has been shown that there is a correlation between post-traumatic stress symptom severity and motivation to use marijuana in order to cope with emotional distress (Bonn-Miller et al., 2007). Although the majority of the currently available clinical studies highlights the beneficial effects of cannabis use in PTSD patients, the positive association between cannabis use and relief from PTSD symptoms is not an universal finding. Thus, it has also been documented that, in certain conditions, cannabis abuse may facilitate PTSD development (Cougle et al., 2011). This may be due to the fact that direct activation of cannabinoid receptors by the active ingredient of cannabis Delta-9-tetrahydrocannabinol leads to a rapid downregulation of the endocannabinoid signaling system (Hirvonen et al., 2012), resulting in tolerance. The complex scenario that emerges from the clinical setting makes it difficult to draw final conclusions about the relationship between cannabis use and PTSD. Preclinical studies allow to control for the confounding variables that characterize the clinical observations, and therefore can provide essential information to elucidate the link between endocannabinoids and emotional memory processing, from physiological to pathological conditions. Thus, as highlighted above, it has been demonstrated that cannabinoid compounds strongly facilitate memory extinction in animals (Marsicano et al., 2002; Lutz, 2007), while impairing memory retrieval (Niyuhire et al., 2007; Atsak et al., 2012). It is thus tempting to speculate that cannabinoid compounds can attenuate the excessive retrieval of the traumatic event experienced by PTSD patients, while facilitating its extinction. Memory consolidation for emotionally salient events is also affected by cannabinoid drugs, although the results of the preclinical studies performed so far are controversial. Thus, it has been shown that post-training administration of cannabinoid receptor direct or indirect agonists facilitates memory consolidation in the inhibitory avoidance task (Campolongo et al., 2009a; Hauer et al., 2011). These findings suggest that activation of cannabinoid receptors shortly after experiencing a stressful event could facilitate the development of 
maladaptive memories of this event. This, in turn, may provide preclinical rationale to the finding that the use of drugs indirectly enhancing endocannabinoid activity, such as propofol, or the use/abuse of cannabis, shortly after the experience of an aversive event, may facilitate PTSD development in humans and has to be avoided in the aftermath of an aversive experience (Cougle et al., 2011; Hemmings and Mackie, 2011; Usuki et al., 2012). However, cannabinoid agonists administered to rats shortly after exposure to a series of intense stressful events have been reported to prevent the impairment in avoidance extinction induced by the traumatic experience (Ganon-Elazar and Akirav, 2009, 2012, 2013). These findings leave open the possibility that cannabinoid drugs may be good candidates for secondary prevention of PTSD, that is, may be a good therapeutic option immediately after trauma exposure (Zohar et al., 2011). It clearly appears from this scenario that, if from one side the data about the effects of cannabinoid drugs on memory retrieval and extinction are quite consistent and suggest that these compounds may facilitate PTSD recovery, on the other side the role of cannabinoids in memory consolidation is still debated. More research is therefore warranted to determine the extent to which differences in doses, routes of administration, timing of exposure and behavioral tasks used may be responsible for the opposite effects of cannabinoid agonists on memory consolidation reported so far. Conversely, encouraging clinical data exist on the use of cannabinoid compounds after the onset of the pathology (weeks or months after the experience of a traumatic event, when the memory consolidation of the traumatic event is completed) (Passie et al., 2012). A recent clinical trial to evaluate the effects of nabilone, a cannabinoid receptor agonist, on treatment-resistant nightmares in PTSD patients demonstrated that the majority of patients $(72 \%)$ receiving nabilone experienced either cessation of nightmares or a significant reduction in nightmare intensity (Fraser, 2009). Subjective improvement in sleep time, the quality of sleep, and the reduction of daytime flashbacks were also noted by some patients (Fraser, 2009). This is the first report of the use of nabilone for the management

\section{REFERENCES}

Akirav, I. (2011). The role of cannabinoids in modulating emotional and non-emotional memory processes in the hippocampus. Front. Behav. Neurosci. 5:34. doi: 10.3389/fnbeh.2011.00034

Albucher, R. C., and Liberzon, I. (2002). Psychopharmacological treatment in PTSD: a critical review. J. Psychiatr. Res. 36, 355-367. doi: 10.1016/S0022-3956(02)00058-4

Ashton, J. C. (2012). Synthetic cannabinoids as drugs of abuse. Curr. Drug Abuse Rev. 5, 158-168. doi: 10.2174/1874473711205020158

Atsak, P., Roozendaal, B., and Campolongo, P. (2012). Role of the endocannabinoid system in regulating glucocorticoid effects on memory for emotional experiences. Neuroscience 204, 104-116. doi: 10.1016/j.neuroscience.2011.08.047

of treatment-resistant nightmares in PTSD. Although this evidence is encouraging, further studies on larger cohorts and with a more accurate identification of possible side effects of chronic use of direct cannabinoid agonists are warranted. The use of drugs that directly bind and activate brain cannabinoid receptors is indeed limited by their abuse potential (Tanda and Goldberg, 2003; Economidou et al., 2007; Ashton, 2012). Two alternative pharmacological approaches exist to target cannabinoid receptors in the brain, without inducing abuse liability (Gobbi et al., 2005; Bortolato et al., 2006; Justinova et al., 2008). First, it has recently been reported that the non-psychotomimetic constituent of cannabis cannabidiol facilitates disruption of contextual fear memories (Stern et al., 2012) in rats while inducing anti-anxiogenic-like effects in rats and humans (Bitencourt et al., 2008; Bergamaschi et al., 2011). Alternatively, several preclinical studies have identified endocannabinoid deactivation inhibitors as a novel therapeutic approach for the treatment of neuropsychiatric disorders. In particular, indirect cannabinoid agonists have been proposed as anxiolitic and antidepressant agents (Kathuria et al., 2003; Bortolato et al., 2006; Piomelli et al., 2006; Vinod and Hungund, 2006) and have been reported to facilitate extinction of fear memory in rodents (Bitencourt et al., 2008; Pamplona et al., 2008). Thus, these compounds may prove effective to ameliorate the anxiety symptoms of PTSD and, at the same time, an increase in the endocannabinoid tone may be useful to treat the cognitive features (Varvel et al., 2007) of the pathology. These dual effects make these drugs gold candidates in the treatment and prevention of PTSD. Much attention, however, has to be dedicated to the time framing of pharmacological treatment, with an attempt to avoid the first early phases of memory consolidation.

It clearly appears that a deeper insight into the role of endocannabinoid neurotransmission in emotional memory processing, both in physiological and pathological conditions, will shed light in the neurobiological basis of PTSD; this, in turn, will open new frontiers for alternative and more efficacious therapeutic approaches for a complete resolution of the pathology.

cannabidiol in conditioned rats. Eur. Neuropsychopharmacol. 18, 849-859. doi: 10.1016/j.euroneuro. 2008.07.001

Bonn-Miller, M. O., Vujanovic, A. A., and Drescher, K. D. (2011). Cannabis use among military veterans after residential treatment for posttraumatic stress disorder. Psychol. Addict. Behav. 25, 485-491. doi: 10.1037/a0021945

Bonn-Miller, M. O., Vujanovic, A. A., Feldner, M. T., Bernstein, A., and Zvolensky, M. J. (2007). Posttraumatic stress symptom severity predicts marijuana use coping motives among traumatic event-exposed marijuana users. J. Trauma. Stress 20, 577-586. doi: 10.1002/jts. 20243

Bortolato, M., Campolongo, P., Mangieri, R. A., Scattoni, M. L., Frau, R., Trezza, V., et al. (2006).
Anxiolytic-like properties of the anandamide transport inhibitor AM404. Neuropsychopharmacology 31, 2652-2659. doi: 10.1038/sj.npp. 1301061

Bremner, J. D., Elzinga, B., Schmahl, C., and Vermetten, E. (2008). Structural and functional plasticity of the human brain in posttraumatic stress disorder. Prog. Brain Res. 167, 171-186. doi: 10.1016/S0079-6123(07)67012-5

Bremner, J. D., Southwick, S. M., Darnell, A., and Charney, D. S. (1996). Chronic PTSD in Vietnam combat veterans: course of illness and substance abuse. Am. J. Psychiatry 153, 369-375.

Brewin, C. R. (2001). A cognitive neuroscience account of posttraumatic stress disorder and its treatment. Behav. Res. Ther. 39, 373-393. doi: 10.1016/S0005-7967(00)00087-5 
Campolongo, P., Morena, M., Scaccianoce, S., Trezza, V., Chiarotti, F., Schelling, G., et al. (2013). Novelty-induced emotional arousal modulates cannabinoid effects on recognition memory and adrenocortical activity. Neuropsychopharmacology 38, 1276-1286. doi: 10.1038/npp. 2013.26

Campolongo, P., Ratano, P., Manduca, A., Scattoni, M. L., Palmery, M., Trezza, V., et al. (2012). The endocannabinoid transport inhibitor AM404 differentially modulates recognition memory in rats depending on environmental aversiveness. Front. Behav. Neurosci. 6:11. doi: 10.3389/fnbeh.2012.00011

Campolongo, P., Roozendaal, B., Trezza, V., Hauer, D., Schelling, G., McGaugh, J. L., et al. (2009a). Endocannabinoids in the rat basolateral amygdala enhance memory consolidation and enable glucocorticoid modulation of memory. Proc. Natl. Acad. Sci. U.S.A. 106, 4888-4893. doi: 10.1073/pnas.0900835106

Campolongo, P., Trezza, V., Palmery, M., Trabace, L., and Cuomo, V. (2009b). Developmental exposure to cannabinoids causes subtle and enduring neurofunctional alterations. Int. Rev. Neurobiol. 85, 117-133. doi: 10.1016/S0074-7742(09)85009-5

Campolongo, P., Trezza, V., Cassano, T., Gaetani, S., Morgese, M. G., Ubaldi, M., et al. (2007). Perinatal exposure to delta-9-tetrahydrocannabinol causes enduring cognitive deficits associated with alteration of cortical gene expression and neurotransmission in rats. Addict. Biol. 12, 485-495. doi: 10.1111/j.1369-1600.2007.00074.x

Campolongo, P., Trezza, V., Ratano, P., Palmery, M., and Cuomo, V. (2011). Developmental consequences of perinatal cannabis exposure: behavioral and neuroendocrine effects in adult rodents. Psychopharmacology (Berl.) 214, 5-15. doi: 10.1007/s00213010-1892-x

Cohen, H., Kaplan, Z., Matar, M. A., Loewenthal, U., Kozlovsky, N., and Zohar, J. (2006). Anisomycin, a protein synthesis inhibitor, disrupts traumatic memory consolidation and attenuates posttraumatic stress response in rats. Biol. Psychiatry 60, 767-776. doi: 10.1016/j.biopsych.2006.03.013

Cornelius, J. R., Kirisci, L., Reynolds, M., Clark, D. B., Hayes, J., and Tarter, R. (2010). PTSD contributes to teen and young adult cannabis use disorders. Addict. Behav. 35, 91-94. doi: 10.1016/j.addbeh.2009.09.007

Cougle, J. R., Bonn-Miller, M. O., Vujanovic, A. A., Zvolensky, M J., and Hawkins, K. A. (2011). Posttraumatic stress disorder and cannabis use in a nationally representative sample. Psychol. Addict. Behav. 25, 554-558. doi: 10.1037/a0023076

Darves-Bornoz, J. M., Alonso, J., De Girolamo, G., De Graaf, R., Haro, J. M., Kovess-Masfety, V., et al. (2008). Main traumatic events in Europe: PTSD in the European study of the epidemiology of mental disorders survey. J. Trauma. Stress 21, 455-462. doi: 10.1002/jts.20357

de Oliveira Alvares, L., De Oliveira, L. F., Camboim, C., Diehl, F., Genro, B. P., Lanziotti, V. B., et al. (2005). Amnestic effect of intrahippocampal AM251, a CB1-selective blocker, in the inhibitory avoidance, but not in the open field habituation task, in rats. Neurobiol. Learn. Mem. 83, 119-124. doi: 10.1016/j.nlm.2004.10.002

de Oliveira Alvares, L., Pasqualini Genro, B., Diehl, F., Molina, V. A., and Quillfeldt, J. A. (2008). Opposite action of hippocampal CB1 receptors in memory reconsolidation and extinction. Neuroscience 154, 1648-1655. doi 10.1016/j.neuroscience.2008.05.005

de Quervain, D. J., Aerni, A., Schelling, G., and Roozendaal, B. (2009). Glucocorticoids and the regulation of emotional memory in health and disease. Front. Neuroendocrinol. 30, 358-370. doi 10.1016/j.yfrne.2009.03.002

Di Marzo, V., De Petrocellis, L., and Bisogno, T. (2005). The biosynthesis, fate and pharmacological properties of endocannabinoids. Handb. Exp. Pharmacol. 168, 147-185. doi: 10.1007/3-540-26573-2_5

Dow, B., and Kline, N. (1997). Antidepressant treatment of posttraumatic stress disorder and major depression in veterans. Ann. Clin. Psychiatry 9, 1-5. doi: 10.3109/10401239709147767

Economidou, D., Mattioli, L., Ubaldi, M., Lourdusamy, A., Soverchia, L., Hardiman, G., et al. (2007). Role of cannabinoidergic mechanisms in ethanol selfadministration and ethanol seeking in rat adult offspring following perinatal exposure to Delta9tetrahydrocannabinol. Toxicol. Appl. Pharmacol. 223, 73-85. doi: 10.1016/j.taap.2007.05.008

Egerton, A., Allison, C., Brett, R. R., and Pratt, J. A. (2006).
Cannabinoids and prefrontal cortical function: insights from preclinical studies. Neurosci. Biobehav. Rev. 30, 680-695. doi 10.1016/j.neubiorev.2005.12.002

Fernandez-Ruiz, J., Berrendero, F., Hernandez, M. L., and Ramos, J. A (2000). The endogenous cannabinoid system and brain development. Trends Neurosci. 23, 14-20. doi: 10.1016/S0166-2236(99)01491-5

Fraser, G. A. (2009). The use of a synthetic cannabinoid in the management of treatment-resistant nightmares in posttraumatic stress disorder (PTSD). CNS Neurosci. Ther. 15, 84-88. doi 10.1111/j.1755-5949.2008.00071.x

Ganon-Elazar, E., and Akirav, I. (2009). Cannabinoid receptor activation in the basolateral amygdala blocks the effects of stress on the conditioning and extinction of inhibitory avoidance. J. Neurosci. 29, 11078-11088. doi 10.1523/JNEUROSCI.1223-09.2009

Ganon-Elazar, E., and Akirav, I. (2012). Cannabinoids prevent the development of behavioral and endocrine alterations in a rat model of intense stress. Neuropsychopharmacology 37, 456-466. doi: 10.1038/npp. 2011.204

Ganon-Elazar, E., and Akirav, I. (2013). Cannabinoids and traumatic stress modulation of contextual fear extinction and GR expression in the amygdalahippocampal-prefrontal circuit. Psychoneuroendocrinology. doi: 10. 1016/j.psyneuen.2013.01.014. [Epub ahead of print]

Gobbi, G., Bambico, F. R., Mangieri, R., Bortolato, M., Campolongo, P., Solinas, M., et al. (2005). Antidepressant-like activity and modulation of brain monoaminergic transmission by blockade of anandamide hydrolysis. Proc. Natl. Acad. Sci. U.S.A. 102, 18620-18625. doi: 10.1073/pnas.0509591102

Goodman, J., Leong, K. C., and Packard, M. G. (2012). Emotional modulation of multiple memory systems: implications for the neurobiology of post-traumatic stress disorder. Rev. Neurosci. 23, 627-643. doi: 10.1515/revneuro-2012-0049

Haller, J., Bakos, N., Szirmay, M. Ledent, C., and Freund, T. F. (2002). The effects of genetic and pharmacological blockade of the CB1 cannabinoid receptor on anxiety. Eur. J. Neurosci. 16, 1395-1398. doi: $\quad 10.1046 / j .1460-9568$ 2002.02192.x

Haller, J., Varga, B., Ledent, C., Barna, I., and Freund, T. F. (2004). Context-dependent effects of
CB1 cannabinoid gene disruption on anxiety-like and social behaviour in mice. Eur. J. Neurosci. 19, 1906-1912. doi: 10.1111/j.1460-9568.2004.03293.x

Harkany, T., Guzman, M., GalveRoperh, I., Berghuis, P., Devi, L. A., and Mackie, K. (2007) The emerging functions of endocannabinoid signaling during CNS development. Trends Pharmacol. Sci. 28, 83-92. doi: 10.1016/j.tips. 2006.12.004

Hauer, D., Ratano, P., Morena, M., Scaccianoce, S., Briegel, I., Palmery, M., et al. (2011). Propofol enhances memory formation via an interaction with the endocannabinoid system. Anesthesiology 114, 1380-1388. doi: 10.1097/ALN.0b013e31821c120e

Hauer, D., Schelling, G., Gola, H., Campolongo, P., Morath, J., Roozendaal, B., et al. (2013). Plasma concentrations of endocannabinoids and related primary fatty acid amides in patients with post-traumatic stress disorder. PLOS ONE 8:e62741. doi: 10.1371/journal.pone.0062741

Hemmings, H. C. Jr., and Mackie, K. (2011). The rivers of Lethe and Mnemosyne converge: propofol and memory consolidation. Anesthesiology 114, 1277-1279. doi: 10.1097/ALN.0b013e31821c647d

Herry, C., Ferraguti, F., Singewald, N., Letzkus, J. J., Ehrlich, I., and Luthi, A. (2010). Neuronal circuits of fear extinction. Eur. J. Neurosci. 31, 599-612. doi: 10.1111/j.14609568.2010.07101.x

Hill, M. N., and Gorzalka, B. B. (2009). The endocannabinoid system and the treatment of mood and anxiety disorders. CNS Neurol. Disord. Drug Targets 8, 451-458. doi: 10.2174/187152709 789824624

Hirvonen, J., Goodwin, R. S., Li, C. T., Terry, G. E., Zoghbi, S. S., Morse, C., et al. (2012). Reversible and regionally selective downregulation of brain cannabinoid CB1 receptors in chronic daily cannabis smokers. Mol. Psychiatry 17, 642-649. doi: 10.1038/mp.2011.82

Hughes, K. C., and Shin, L. M. (2011). Functional neuroimaging studies of post-traumatic stress disorder. Expert Rev. Neurother. 11, 275-285. doi: 10.1586/ern.10.198

Ipser, J. C., Carey, P., Dhansay, Y., Fakier, N., Seedat, S., and Stein, D. J. (2006). Pharmacotherapy augmentation strategies in treatment-resistant anxiety disorders. Cochrane Database Syst. Rev CD005473 
Javidi, H., and Yadollahie, M. (2012). Post-traumatic stress disorder. Int. J. Occup. Environ. Med. 3, 2-9.

Justinova, Z., Mangieri, R. A., Bortolato, M., Chefer, S. I., Mukhin, A. G., Clapper, J. R., et al. (2008). Fatty acid amide hydrolase inhibition heightens anandamide signaling without producing reinforcing effects in primates. Biol. Psychiatry 64, 930-937. doi: 10.1016/j.biopsych. 2008.08.008

Kathuria, S., Gaetani, S., Fegley, D., Valino, F., Duranti, A., Tontini, A., et al. (2003). Modulation of anxiety through blockade of anandamide hydrolysis. Nat. Med. 9, 76-81. doi: 10.1038/nm803

Kessler, R. C., Sonnega, A., Bromet, E., Hughes, M., and Nelson, C. B. (1995). Posttraumatic stress disorder in the National Comorbidity Survey. Arch. Gen. Psychiatry 52, 1048-1060. doi: 10.1001/archpsyc. 1995.03950240066012

Layton, B., and Krikorian, R. (2002). Memory mechanisms in posttraumatic stress disorder. J. Neuropsychiatry Clin. Neurosci. 14, 254-261. doi: 10.1176/ appi.neuropsych.14.3.254

Lutz, B. (2007). The endocannabinoid system and extinction learning. Mol. Neurobiol. 36, 92-101. doi: $10.1007 /$ s12035-007-8004-x

Marsicano, G., and Lafenetre, P. (2009). Roles of the endocannabinoid system in learning and memory. Curr. Top. Behav. Neurosci. 1, 201-230. doi: 10.1007/978-3-54088955-7_8

Marsicano, G., Wotjak, C. T., Azad, S. C., Bisogno, T., Rammes, G., Cascio, M. G., et al. (2002). The endogenous cannabinoid system controls extinction of aversive memories. Nature 418, 530-534. doi: 10.1038/nature00839

McGaugh, J. L. (2004). The amygdala modulates the consolidation of memories of emotionally arousing experiences. Annu. Rev. Neurosci. 27, 1-28. doi: 10.1146/annurev. neuro.27.070203.144157

Moreira, F. A., and Wotjak, C. T. (2010). Cannabinoids and anxiety. Curr. Top. Behav. Neurosci. 2, 429-450. doi: 10.1007/7854_2009_16

Neumeister, A. (2013). The endocannabinoid system provides an avenue for evidence-based treatment development for PTSD. Depress. Anxiety 30, 93-96. doi: $10.1002 /$ da. 22031
Neumeister, A., Normandin, M. D., Pietrzak, R. H., Piomelli, D., Zheng, M. Q., Gujarro-Anton, A., et al. (2013). Elevated brain cannabinoid $\mathrm{CB} 1$ receptor availability in post-traumatic stress disorder: a positron emission tomography study. Mol. Psychiatry. doi: 10.1038/mp.2013.61. [Epub ahead of print].

Niyuhire, F., Varvel, S. A., Martin, B. R., and Lichtman, A. H. (2007). Exposure to marijuana smoke impairs memory retrieval in mice. J. Pharmacol. Exp. Ther. 322, 1067-1075. doi: 10.1124/jpet.107.119594

Packard, M. G., and Goodman, J. (2012). Emotional arousal and multiple memory systems in the mammalian brain. Front. Behav. Neurosci. 6:14. doi: 10.3389/fnbeh.2012.00014

Pamplona, F. A., Bitencourt, R. M., and Takahashi, R. N. (2008). Shortand long-term effects of cannabinoids on the extinction of contextual fear memory in rats. Neurobiol. Learn. Mem. 90, 290-293. doi: 10.1016/j.nlm.2008.04.003

Parolaro, D., Realini, N., Vigano, D., Guidali, C., and Rubino, T. (2010). The endocannabinoid system and psychiatric disorders. Exp. Neurol. 224, 3-14. doi: 10.1016/j.expneurol.2010.03.018

Parsons, R. G., and Ressler, K. J. (2013). Implications of memory modulation for post-traumatic stress and fear disorders. Nat. Neurosci. 16, 146-153. doi: 10.1038/nn.3296

Passie, T., Emrich, H. M., Karst, M., Brandt, S. D., and Halpern, J. H. (2012). Mitigation of posttraumatic stress symptoms by Cannabis resin: a review of the clinical and neurobiological evidence. Drug Test. Anal. 4, 649-659. doi: $10.1002 /$ dta. 1377

Piomelli, D. (2003). The molecular logic of endocannabinoid signalling. Nat. Rev. Neurosci. 4, 873-884. doi: 10.1038/nrn1247

Piomelli, D., Tarzia, G., Duranti, A., Tontini, A., Mor, M., Compton, T. R., et al. (2006). Pharmacological profile of the selective FAAH inhibitor KDS-4103 (URB597). CNS Drug Rev. 12, 21-38. doi: 10.1111/j.1527-3458.2006.00021.x

Quirk, G. J., and Mueller, D. (2008). Neural mechanisms of extinction learning and retrieval. Neuropsychopharmacology 33, 56-72. doi: 10.1038/sj.npp.1301555
Riedel, G., and Davies, S. N. (2005). Cannabinoid function in learning, memory and plasticity. Handb. Exp. Pharmacol. 168, 445-477. doi: 10.1007/3-540-26573-2_15

Roozendaal, B., Barsegyan, A., and Lee, S. (2008). Adrenal stress hormones, amygdala activation, and memory for emotionally arousing experiences. Prog. Brain Res. 167, 79-97. doi: 10.1016/S0079-6123 (07)67006-X

Ruehle, S., Rey, A. A., Remmers, F., and Lutz, B. (2012). The endocannabinoid system in anxiety, fear memory and habituation. J. Psychopharmacol. (Oxford) 26, 23-39. doi: $10.1177 / 0269881111408958$

Schelling, G., Stoll, C., Haller, M., Briegel, J., Manert, W., Hummel, T., et al. (1998). Health-related quality of life and posttraumatic stress disorder in survivors of the acute respiratory distress syndrome. Crit. Care Med. 26, 651-659. doi: 10.1097/00003246199804000-00011

Stern, C. A., Gazarini, L., Takahashi, R. N., Guimaraes, F. S., and Bertoglio, L. J. (2012). On disruption of fear memory by reconsolidation blockade: evidence from cannabidiol treatment. Neuropsychopharmacology 37, 2132-2142. doi: 10.1038/npp. 2012.63

Stewart, S. H., Pihl, R. O., Conrod, P. J. and Dongier, M. (1998). Functional associations among trauma, PTSD, and substance-related disorders. Addict. Behav. 23, 797-812. doi: 10.1016/S0306-4603(98)00070-7

Tanda, G., and Goldberg, S. R. (2003). Cannabinoids: reward, dependence, and underlying neurochemical mechanisms-a review of recent preclinical data. Psychopharmacology (Berl.) 169, 115-134. doi: 10.1007/s00213-003-1485-z

Trezza, V., Campolongo, P., Cassano, T., Macheda, T., Dipasquale, P., Carratu, M. R., et al. (2008). Effects of perinatal exposure to delta-9-tetrahydrocannabinol on the emotional reactivity of the offspring: a longitudinal behavioral study in Wistar rats. Psychopharmacology (Berl.) 198, 529-537. doi: 10.1007/s00213-0081162-3

Usuki, M., Matsuoka, Y., Nishi, D., Yonemoto, N., Matsumura, K. Otomo, Y., et al. (2012). Potential impact of propofol immediately after motor vehicle accident on later symptoms of posttraumatic stress disorder at 6-month follow up: a retrospective cohort study. Crit. Care 16:R196. doi: 10.1186/cc11681

Van Ameringen, M., Mancini, C., Patterson, B., and Boyle, M. H. (2008). Post-traumatic stress disorder in Canada. CNS Neurosci. Ther. 14, 171-181. doi: 10.1111/j.17555949.2008.00049.x

Varvel, S. A., Wise, L. E., Niyuhire, F., Cravatt, B. F., and Lichtman, A. H. (2007). Inhibition of fatty-acid amide hydrolase accelerates acquisition and extinction rates in a spatial memory task. Neuropsychopharmacology 32, 1032-1041. doi: 10.1038/sj.npp. 1301224

Vinod, K. Y., and Hungund, B. L. (2006). Role of the endocannabinoid system in depression and suicide. Trends Pharmacol. Sci. 27, 539-545. doi: 10.1016/j.tips. 2006.08.006

Zohar, J., Juven-Wetzler, A., Sonnino, R., Cwikel-Hamzany, S., Balaban, E., and Cohen, H. (2011). New insights into secondary prevention in post-traumatic stress disorder. Dialogues Clin. Neurosci. 13, 301-309.

Conflict of Interest Statement: The authors declare that the research was conducted in the absence of any commercial or financial relationships that could be construed as a potential conflict of interest.

Received: 19 June 2013; accepted: 19 July 2013; published online: 09 August 2013. Citation: Trezza $V$ and Campolongo P (2013) The endocannabinoid system as a possible target to treat both the cognitive and emotional features of posttraumatic stress disorder (PTSD). Front. Behav. Neurosci. 7:100. doi: 10.3389/ fnbeh.2013.00100

Copyright (C) 2013 Trezza and Campolongo. This is an open-access article distributed under the terms of the Creative Commons Attribution License (CC BY). The use, distribution or reproduction in other forums is permitted, provided the original author(s) or licensor are credited and that the original publication in this journal is cited, in accordance with accepted academic practice. No use, distribution or reproduction is permitted which does not comply with these terms. 